\title{
Gubernamentalidad corporativa y despolitización del reasentamiento de Morococha: una aproximación etnográfica
}

Fabio Miranda*

* Licenciado en Antropología por la Pontificia Universidad Católica del Perú, actualmente cursando estudios de maestría en la Universidad de Osaka, Japón. Correo electrónico: fdmiranda16@gmail.com

Fecha de recepción: 01/03/18. Fecha de aceptación: 09/11/18 


\title{
Gubernamentalidad corporativa y despolitización del reasentamiento de Moro- cocha: una aproximación etnográfica
}

\section{RESUMEN}

El artículo describe el proceso de reasentamiento de la ciudad de Morococha, en la provincia altoandina de Yauli, en Junín, así como la trayectoria histórica de la localidad como ciudad-empresa y su centralidad en el desarrollo del eje minero-metalúrgico de la sierra central. Asimismo, se analizan críticamente los discursos que enmarcan al sujeto de desplazamiento por la empresa minera y el sentido de comunidad de la población, con la finalidad de desentrañar los términos en los cuales se organizan las diferencias sociales. El artículo concluye con algunos alcances sobre la despolitización del proceso de reasentamiento como parte de las nuevas formas de gubernamentalidad corporativa, el desfase entre los discursos endógenos sobre pertenencia y las prácticas de identificación de afectados por la empresa.

Palabras clave: reasentamiento involuntario, minería, gubernamentalidad, sujeto, Andes.

Corporate governmentality and depoliticization in the resettlement of Morococha: An ethnographic approach

\begin{abstract}
The article describes the process of resettlement in Morococha, in the highland province of Yauli in Junín as well as its historical trajectory as a mining town pivotal to the development of the miningmetallurgic axis in the central highlands of Peru. Additionally, the article critically analyzes mining company discourse that frames the displaced subject and the construction of the sense of community in order to disentangle the terms in which social difference is organized. The article concludes with some insights on the depoliticization of the resettlement process as part of the new forms of corporate governmentality and the gap between endogenous discourses about belonging and practices of identification of affected individuals.
\end{abstract}

Keywords: involuntary resettlement, mining, governmentality, subject, Andes. 


\section{INTRODUCCIÓN $^{1}$}

El año 2012 inauguró la fase de traslado de cientos de familias de la ciudad de Morococha, un pueblo minero ubicado sobre los $4600 \mathrm{msnm}$ en el eje minerometalúrgico de La Oroya, a unas tres horas de Lima. En medio del extremo clima de montaña y una creciente precariedad física y legal, estas familias habían estado negociando los términos del reasentamiento durante aproximadamente seis ańos. El proceso estuvo marcado por acusaciones de manipulación contra la empresa minera Chinalco y de corrupción de dirigentes, así como por episodios de violencia y represión policial. La población de Morococha, conformada por trabajadores mineros, sus descendientes y comerciantes, encaró el complejo proceso de reasentamiento sin una base cohesionada ni dirigentes políticos que le permitiesen articular la multiplicidad de intereses existentes.

\section{Figura 1. Ubicación del proyecto}

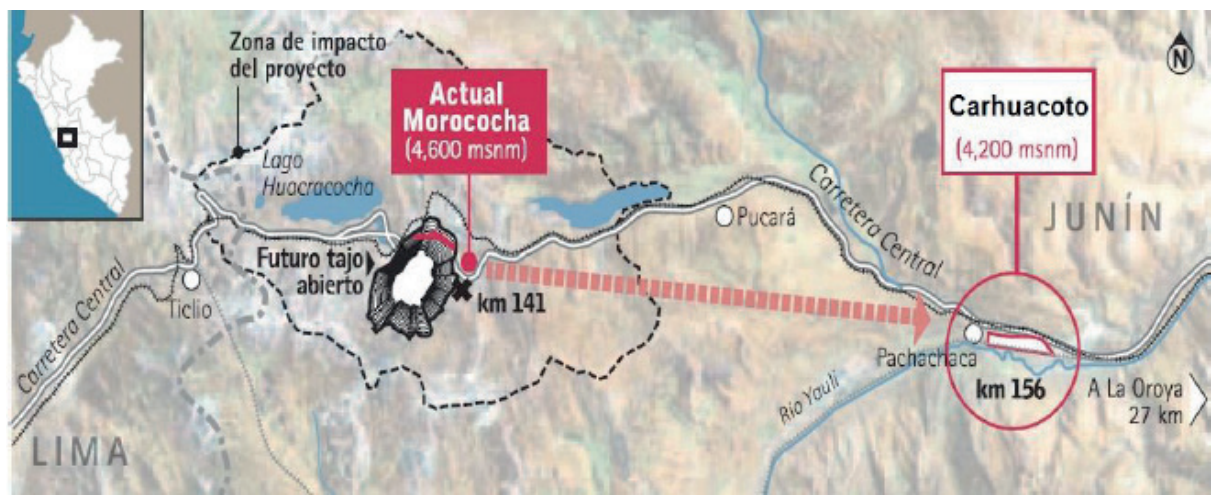

Fuente: Adaptado de mapa publicado en diario La República, 2012. http://vidasverdes.blogspot.com/2012/11/ chinalco-un-atropello-mas-en-morococha.html

El foco de atención de este artículo no será la negociación con la empresa minera, aunque presentaré una corta narración cronológica para contextualizar los hechos. El objeto de discusión es la construcción del sujeto y el sentido de comunidad en Morococha a partir de la irrupción generada por el reasentamiento en el entramado social de las personas afectadas. De este modo, el artículo explora las coordenadas de diferenciación social que dieron lugar a esta divergencia a partir del análisis de algunas categorías culturales encontradas durante el trabajo de campo, con el objetivo de analizar formas emergentes de gubernamentalidad corporativa

\footnotetext{
Este artículo está basado en la tesis de licenciatura Politicas de lugar en Morococha: el contexto del reasentamiento por el proyecto minero Toromocho (2016). Disponible en http://tesis.pucp.edu.pe/ repositorio/handle/123456789/9179.
} 
mediante prácticas de responsabilidad social empresarial (Smith y Helfgott, 2010; Himley, 2012) en un contexto de flexibilización y precarización de la fuerza laboral. La noción foucaultiana de gubernamentalidad (Foucault, 1979) refiere al estudio de racionalidades políticas de gobierno, es decir, las distintas lógicas que siguen los Estados para ejercer el control de sus sociedades constituyentes. Un rasgo fundamental de gubernamentalidad moderna es el recurso a la biopolítica, término mediante el cual Foucault (2000) analiza el paso del régimen disciplinario (basado en la vigilancia y el castigo) al normalizador (basado en el establecimiento de regulaciones de la vida como fenómeno). En ese sentido, la gubernamentalidad corporativa aparece como la apropiación neoliberal del conjunto de aparatos y técnicas biopolíticas tradicionalmente asociadas al Estado.

La gubernamentalidad corporativa, entonces, desenfatiza la capacidad del poder soberano de establecer la ley, poniendo mayor importancia en el establecimiento de objetos de saber relacionados con la población. Su ejercicio requiere, más allá de la imposición o coerción por la fuerza (aunque sin prescindir de ella), la participación de los sujetos sociales en su autogobierno y la producción de subjetividades específicas. Analizar la gubernamentalidad requiere trazar los cambios, transiciones y continuidades en las lógicas de gobierno (Huxley, 2008) que problematizan las relaciones de las personas con las cosas, costumbres y eventos, con el fin de intervenir de manera efectiva en ellas y para ajustarlas a una racionalidad definida previamente.

El caso analizado deja entrever una porosidad del poder del Estado, cuya actividad se encuentra atravesada por diversos actores. La gubernamentalidad es así ya no solo un asunto del Estado, sino que compete a otros actores poderosos que intervienen en la sociedad civil (Ferguson y Gupta, 2002). De este modo, el artículo ahonda en los mecanismos discursivos empleados por la empresa minera y las instituciones responsables de los asuntos sociales con respecto a la población. Específicamente hablamos de una homogenización que invisibiliza las diferencias sociales bajo un manto de pobreza generalizada que finalmente termina justificando el reasentamiento en nombre del desarrollo. Asimismo, se analiza críticamente el despliegue del dispositivo de riesgo geológico como una técnica de gobierno sobre los sujetos del desplazamiento.

El artículo está basado en el seguimiento documentario del caso a partir del ańo 2012 y el trabajo de campo realizado entre agosto y noviembre de 2015, cuando se realizó observación participante y entrevistas en profundidad con diversos actores (funcionarios y afectados por el reasentamiento). Los informantes, alrededor de cuarenta personas, fueron seleccionados en función de su participación en el proceso: se procuró conversar con gente que permanecía en la antigua ciudad tanto como con aquellos que habían decidido mudarse. Se usó un muestreo por bola de nieve, estableciendo una cadena de referencia a partir de dos informantes aleatorios 
en cada categoría. Los funcionarios fueron aproximados mediante solicitud formal in situ con la compañía. Complementariamente, se revisó material impreso de la empresa minera Chinalco (boletines informativos de circulación general) y de normativa oficial disponible en línea.

\section{En los dOMinios de la CERro: enClaVes CAPITALISTAS Y TERRITORIOS DE EXCEPCIÓN}

$\mathrm{Al}$ igual que todo fenómeno social, no se puede explicar a situación de Morococha sin comprender la historia regional y local, así como los procesos de articulación económica que permitieron el crecimiento de las ciudades del eje minero-metalúrgico de la sierra central. El Perú de inicios del siglo XX se insertó en el sistema capitalista a través de una economía exportadora asentada en la organización de enclaves productivos y extractivos. Fueron cuatro complejos los que se desarrollaron en este período: en la costa norte, la agroindustria creció con haciendas azucareras como Casa Grande, de la empresa Gildemeister (Contreras y Hernández, 2017). Por su parte, el complejo petrolero de la International Petroleum Company asumió el mismo rol en la industria de hidrocarburos con su centro de refinamiento en Talara (Aranda, 1997, 1998). En Piura, Huaura, Chancay, Ica y la sierra sur, los complejos algodoneros se dedicaron al acopio de fibras para la industria textil (Sulmont, 1974, p. 39; Burga y Flores Galindo, 1991[1980]), pp. 33-46). En el caso del complejo minero, la Cerro de Pasco Copper Corporation organizó el espacio de la sierra central en torno a sus necesidades productivas durante buena parte del siglo, hasta su nacionalización por el régimen militar en 1974 sustituyéndola por Centromin Perú (Contreras y Cueto, 2013, pp. 344-345).

Este artículo se enfoca en el último ámbito para narrar una parte de la experiencia de la población de Morococha y tentar una explicación del malestar social suscitado por el reasentamiento poblacional iniciado en la década pasada y que hasta hoy continúa sin conclusión satisfactoria para los afectados. La problemática minera se suele enmarcar dentro de lo que ha venido denominándose como conflictos socioambientales por la expansión de esta actividad en espacios rurales. En escenarios de este tipo, los intereses extractivos encuentran la oposición de movimientos sociales que cuestionan el rol de la inversión minera en sus proyectos de desarrollo territorial (Bebbington et al., 2011). Así, bajo esta tendencia se mapea a los actores enfrentados en dos campos bien delimitados: comunidades campesinas, frentes de defensa y otras colectividades frente a «trabajadores, especialistas de relaciones comunitarias, gerentes de operaciones y otros funcionarios de empresas mineras» (De Echave et al., 2009, p. 9) en torno a disputas por la contaminación del medio ambiente y vulneración de la propiedad comunal. Todo esto contrasta con los antiguos tra- 
bajos sobre minería hasta la década de 1990, en los que primaba el análisis clasista de cuestiones relacionadas con el ámbito del trabajo. Si bien en el caso de Morococha los temas medioambientales han sido elevados como argumento en contra del reasentamiento, la particularidad del caso radica en que se trata de un espacio históricamente marcado por la actividad extractiva y las demandas de la población se encuentran articuladas por cuestiones laborales en un contexto de reducción de mano de obra y debilitamiento de la organización sindical.

Tras sus remotos orígenes como hacienda mineral a finales del siglo XVIII, Morococha recibió el influjo de pequeños mineros de origen europeo o criollo luego de la Guerra del Pacífico, experiencia que abrió camino a la minería industrial de gran escala a inicios del siglo XX. Hacia fines de la década de 1890, las minas de Morococha empezaron a presentar problemas como el agotamiento de las capas superiores de mineral, requiriendo la perforación de túneles cada vez más profundos. Como consecuencia de dificultades de diseńo y aparente negligencia de las empresas ${ }^{2}$, los túneles sufrieron filtraciones de agua (Kruijt y Vellinga, 1988, p. 18) que finalmente marcaron un trágico hito con el derrumbe de las galerías debajo de la hoy extinta laguna de Morococha ${ }^{3}$. En 1905, los norteamericanos James B. Haggin y A. W. MacCune fundaron la Morococha Mining Company. En paralelo, Jacob Backus y Howard Johnston adquirieron varias minas bajo el nombre de Backus \& Johnston Company. Estas dos empresas dominaron el panorama hasta 1913, año en que llega a Morococha la Cerro de Pasco Copper Corporation (CPCC) para abrir su propia unidad de producción.

Poco tiempo después de su fundación en 1901, la CPCC se convirtió en la compañía minera más grande del país. El complejo minero que construyó en la sierra central estuvo constituido por decenas de asientos, así como miles de hectáreas de tierra que fueron destinadas a la producción ganadera adquiridas mediante un agresivo programa de compras de minas de pequeńos y medianos propietarios. De este modo, «la Cerro» expandió sus actividades hacia Casapalca y Morococha, cuya producción conjunta superó la capacidad de procesamiento que poseía hasta ese momento en la fundición de Tinyahuarco, obligándola a renovar sus instalaciones mediante la construcción de una nueva planta en La Oroya.

Cómo se produjo la catástrofe de Morococha. Labor, 4, 29/12/1928, 1. Lima: Amauta.

El derrumbe ocurrido el 5 de diciembre de 1928 fue ampliamente cubierto por medios como la revista Amauta y el quincenario Labor, dirigidos desde Lima por José Carlos Mariátegui. Esta tragedia suscitó el interés de Mariátegui y actuó como catalizador de la organización obrera frente a los abusos de la empresa gracias a la acción de militantes comunistas como Gamaniel Blanco y Jorge del Prado. Sobre este tema, revisar el volumen Jorge del Prado y los mineros de la sierra central. Testimonio sobre la masacre de Malpaso (2010), editado por el Fondo Editorial del Congreso del Perú. En la actualidad, ese día es aprovechado para conmemorar el Día del Minero. 
La población creció vertiginosamente a partir de 1920 y para inicios de la siguiente década los habitantes se contaban por los miles, época que la CPCC dominó indiscutiblemente la vida social de Morococha. En este período empezó la transformación del campamento en "ciudad-empresa». Se usa este término para referir a asentamientos construidos y operados por una única empresa entre $1830 \mathrm{y}$ 1930 con el propósito de albergar a sus trabajadores y, según el caso, a sus familias (Garner, 1992, p. 3). En estos espacios, la vida social suele estar subordinada a la producción y la infraestructura urbana regentada por las compañías. El fenómeno de los enclaves productivos, específicamente en el sector petrolero y minero, fue de la mano con el establecimiento de estas ciudades-empresa que algunos autores han llegado a calificar de territorios de excepción (Aranda, 2009, p. 57), sujetos a regímenes especiales en los cuales la soberanía nacional estaba parcialmente limitada y supeditada a la decisión de los intendentes extranjeros.

En 1968, un grupo de militares liderados por el general Juan Velasco Alvarado asestó un golpe de Estado al gobierno de Fernando Belaunde Terry, estableciendo un gobierno de corte nacionalista. Como parte de la nueva política del régimen, muchas de las grandes empresas controladas por el capital extranjero fueron nacionalizadas. Entre ellas se encontraba la CPCC, cuyas propiedades fueron absorbidas por la Empresa Minera del Centro del Perú (Centromin Perú) partir de 1974. Tras dos décadas de funcionamiento público, la empresa estatal pasó nuevamente a manos privadas gracias a las reformas de Alberto Fujimori. Bajo el programa de minimización de la iniciativa empresarial del Estado y fomento de su «rol subsidiario" (Ruiz, 2002, p. 10), las empresas estatales fueron fragmentadas y vendidas a distintos consorcios. Centromin no fue ajena a esta tendencia, y hacia 1998, buena parte de sus unidades productivas habían sido liquidadas. El turno le llegaría a Morococha, y sus codiciados yacimientos en el cerro Toromocho, en el año 2003 (Sociedad Nacional de Minería Petróleo y Energía, 2003, p. 22).

\section{NEgociando EL DESPLAZAMIENTO: UNA CRONOLOGÍA DEL PROCESO}

El prolongado proceso de negociación sostenido entre la población de Morococha, representada por la municipalidad y un conjunto de organizaciones de la sociedad civil, y la empresa Chinalco tiene sus antecedentes en el ańo 2005. En aquella ocasión se realizó una audiencia pública sobre reasentamiento llevada a cabo a pedido del entonces alcalde distrital Marcial Salomé Ponce. En 2006, Perú Copper, empresa canadiense que sostuvo inicialmente la concesión del proyecto, encargó a la consultora Social Capital Group (SCG) la conducción de las relaciones comunitarias, así como de los estudios sociales requeridos y de sensibilización sobre el reasentamiento. 
En ese año SCG llevó a cabo el primer estudio de línea de base social (LBS), así como la implementación de un proceso de consulta (Sanborn y Dammert, 2013, p. 70). De acuerdo con este estudio, en el año 2006 existían solo 180 propietarios con derechos reconocidos bajo alguna modalidad, aunque no necesariamente legalizados en las instituciones correspondientes, mientras que el resto de personas residían en los campamentos de alguna empresa o alquilaban vivienda. De igual modo, entre los inquilinos se encontró que alrededor de 1646 familias (Sanborn y Dammert, 2013, p. 71) tenían al menos un año de estadía en el distrito. El resto, se desprende, era de reciente llegada. Debido a la diversidad del estatus de vivienda de los habitantes, la empresa decidió realizar una consulta general a todo el pueblo, independientemente de si eran inquilinos, propietarios u ocupantes. De acuerdo con el relato oficial, en la consulta participaron más de dos tercios de la población, que votó favorablemente por el reasentamiento.

La parte más complicada empezó luego de la consulta. Tras la decisión de mover el pueblo, se hizo necesario determinar el tipo, grado y cantidad a la que ascendería la compensación económica de los reasentados. En esta época se inician las tensiones entre los propietarios e inquilinos en torno al derecho que tenían estos últimos a ser indemnizados. Debido a ello se fundó la Asociación de Vivienda de Morococha (AVM) para agrupar a los inquilinos. Posteriormente se decidiría incluir no solo a estos, sino a todo aquel afectado interesado en conseguir una vivienda en la nueva ciudad. En 2006, la AVM elaboró un listado de sus miembros y lo presentó como padrón de afectados.

En 2007, la empresa Chinalco, de capitales estatales chinos, adquiere los derechos del proyecto y decide renovar el contrato con SCG para dar continuidad a sus intervenciones en lo social (Helfgott, 2013, p. 231). En 2008, el 50\% de las viviendas de Morococha fueron compradas por la empresa, sin discriminar por estatus legal, y se dio inicio a la búsqueda del espacio para reubicar a la población. En el año 2009, debido a nuevas regulaciones del gobierno central, Chinalco presentó el Estudio de Impacto Ambiental (EIA), elaborado por la consultora Knight Piésold y SCG. En paralelo, y debido que habían pasado tres años desde el último estudio de línea de base social, la empresa decide actualizarlo mediante un nuevo estudio. Como parte de esta línea de base, además, se actualiza el padrón de afectados de 2006. En el nuevo padrón se incluyó a nuevos residentes de reciente llegada o que habían vuelto tras un período de migración. Con el padrón actualizado, se pasó a hacer una consulta sobre el emplazamiento donde se llevaría a cabo la construcción de la nueva ciudad. Quedaron tres opciones: Carhuacoto (conocida hasta entonces como ex hacienda Pucará), Llantempampa y Pachachaca, cuyos terrenos se encuentran en el vecino distrito de Yauli. Con un $81 \%$ de los votos, Carhuacoto resultó elegido como el sitio de la Nueva Morococha. 
En 2011, Chinalco inició a la construcción de la nueva ciudad, que se inauguró en octubre de 2012. Poco después, promovió el traslado de los primeros vecinos. Con la salida de los primeros reasentados empieza, asimismo, una mayor resistencia al reasentamiento del entonces alcalde y un sector de la población, en su mayoría propietarios (Sanborn y Dammert, 2013, p. 72). La oposición se centraba en cuestionamientos a la calidad de las construcciones y de los suelos de Carhuacoto, así como la insuficiencia del monto de compensación. Junto con el primer traslado se establece la Mesa de Diálogo para el Proceso de Reasentamiento Poblacional de Morococha. En ella se discutieron los términos del reasentamiento con la idea de elaborar un Convenio Marco que pudiera satisfacer las necesidades y requerimientos de la población. Esta última fue representada a través del alcalde distrital y una serie de líderes de la sociedad civil organizada en asociaciones de propietarios, comerciantes, migrantes, transportistas, entre otros.

Tras unas pocas reuniones de la Mesa, el alcalde decidió retirarse alegando una falta de representatividad de las asociaciones civiles, así como de una supuesta parcialización de estas con la empresa. Las reuniones continuaron sin el alcalde, lo que redujo la representatividad de la mesa y su capacidad para llegar a acuerdos satisfactorios. A pesar de la falta del Convenio Marco, Chinalco prosiguió con el traslado de la población restante. Hasta la fecha no se ha llegado a firmar el ansiado convenio, proceso dilatado por años. Aún hoy permanecen en la «antigua» Morococha alrededor de cuarenta familias que siguen reclamando sus derechos.

\section{LA CONSTRUCCión DEL SUJETO DESPLAZAdo}

Los procesos de reasentamiento se apoyan en un conocimiento específico que determinará la forma en que la intervención se llevará a cabo, ponderando las formas en que la población será potencialmente afectada (positiva y negativamente) y cómo deberán ser compensadas por los daños causados. Por ello, esta sección está dedicada a analizar las formas mediante las cuales la empresa minera concibió al sujeto de su intervención y cómo diagnosticó sus necesidades.

Hasta 2006, buena parte de los morocochanos se empleaban en las minas como perforadores y operarios de maquinaria, o alrededor de estas en los múltiples services, como comerciantes supliendo las necesidades de consumo de los mineros, etc. Asimismo, Morococha era vista como un pueblo minero cuya historia e identidad, al igual que varias comunidades mineras alrededor del mundo (Bulmer, 1975) estaba marcada por décadas de lucha política en torno a la categoría de «clase obrera». Durante el reasentamiento, sin embargo, Chinalco no tuvo que lidiar con «trabajadores» sino con una "población» genérica. El rol de las organizaciones obreras fue mínimo y la explicación es motivo de estudios que superan el objetivo de este 
artículo. Ante dicha ausencia, es necesario precisar el proceso mediante el cual la empresa logró constituir una población objetivo adecuada para su intervención en la localidad. La consultora social contratada por la minera construyó al sujeto del reasentamiento como un poblador pobre y amenazado por riesgos naturales. Esta población vulnerable requería una inmediata evacuación para escapar de las amenazas y mejorar su situación económica, alcanzando el desarrollo en otra parte.

Aunque el principal motivo del desplazamiento fue despejar el entorno de la concesión, pues la legislación vigente prohíbe realizar labores con explosivos en las inmediaciones de centro poblados, los funcionarios estatales y oficiales de Chinalco adoptaron un lenguaje desarrollista y de prevención de riesgos para legitimar la intervención. El reasentamiento fue la oportunidad perfecta para demostrar la «voluntad de mejorar» (Murray Li, 2007) Morococha mediante una completa reconstrucción del pueblo en un espacio nuevo, haciendo "borrón y cuenta nueva» con respecto a las deficiencias de la antigua ciudad. A continuación, presentaré los dos principales discursos desplegados durante el proceso: el de "pobreza», principalmente desarrollado por la empresa en sus estudios de impacto ambiental y el de «riesgo geológico», empleado por el Estado y sus agencias de Defensa Civil.

La principal conclusión que se puede extraer de los apartados dedicados al tema social en el EIA del año 2009 es que en Morococha la gente "no vivía bien» (Sanborn y Dammert, 2013, p. 68); es decir, que eran pobres. Para determinar la situación de pobreza de la población se recurrió a diversos indicadores, como el ingreso monetario, empleo y, principalmente, la metodología de Necesidades Básicas Insatisfechas (NBI). Asimismo, se enfatizó en cuestiones como la calidad de las viviendas y el uso de materiales de construcción.

Las observaciones hechas por la consultora son fácilmente comprobables, pues la forma de asentamiento que se desarrolló históricamente se ha prestado para el hacinamiento y deterioro de las viviendas. Asimismo, los intentos de planificación se vieron entorpecidos más de una vez debido a la incertidumbre de la continuidad de la explotación en la zona e incluso, irónicamente, por la creencia de que en un futuro se realizaría algún tipo de reasentamiento. La planificación urbana de Morococha osciló entre una cierta desidia municipal y un limitado interés estratégico de las empresas mineras. Un entrevistado versado en el tema municipal da su parecer sobre la planificación de la ciudad:

La mayoría de los alcaldes que pasaron estuvieron al servicio de la Cerro de Pasco, y como en el año 1967 descubren Toromocho, ya tenían el plan de un reasentamiento de todo Morococha. Entonces, salió la ley 2211 si no me equivoco, sale esa ley y el Congreso determina que mande a los seńores que se van a encargar de levantar un plan topográfico para darles el título de propiedad a los que ya habían hecho vivienda, pero fue una ley y nunca se cumplió. 
Este pasaje nos da una imagen de un pueblo cuya expansión y crecimiento se encuentra subordinado a las necesidades de la empresa. Ya en la década de 1960, cuando se tenía noticia de los yacimientos de Toromocho se pensaba trasladar a los trabajadores de los campamentos en Morococha a otro lugar no determinado. Dada esta situación precaria y de ocupación permanentemente incierta, la planificación estaba limitada a aquello que las empresas hicieran con sus campamentos. Por ejemplo, en 1986, Centromin analizó las tendencias demográficas desde 1961 y proyectó que en las próximas décadas habría alrededor de 16000 habitantes en el núcleo urbano de Morococha. Si los trabajadores permanecían en Morococha, Centromin debía implementar diversas medidas para albergar a la población a partir de una «racionalización de las inversiones necesarias para el acondicionamiento de los asentamientos humanos y la cobertura de los déficits de vivienda» a través de programas de «erradicación, reubicación y rehabilitación urbana» (Herrera, 1986, p. 5). Del mismo modo, previendo limitaciones en las áreas de expansión, se propuso reubicar a los trabajadores fuera del distrito (Herrera, 1986, p. 40).

Por otro lado, servicios públicos como agua y electricidad se mencionan como evidencia de la pobreza a la que está sujeta la población. Según los datos recogidos por la consultora, un $98,6 \%$ de las viviendas tenía alumbrado público, mientras que el $67 \%$ tenía acceso al agua a través de pilones de uso público. Solo el 15,7\% tenía instalado el servicio de agua dentro de la vivienda (Knight Piésold, 2009, pp. 10-27). Adicionalmente, un grupo grande de habitantes recibía agua a través de cilindros repartidos por la municipalidad.

Con estos indicadores se determinó que el 45,5\% de los hogares de Morococha era pobre con al menos una NBI, mientras que el 12,6\% está en extrema pobreza (dos NBI). El mismo informe indica que el 54,5\% de los hogares no tiene ninguna NBI y que por lo tanto eran no-pobres (Knight Piésold, 2009, pp. 3-506). A la larga resulta algo contradictorio el énfasis que puso la empresa sobre la prevalencia de pobreza en la zona cuando se indica en el mismo texto que más de la mitad de la población no se encontraba en esta situación. El criterio para señalar quién era pobre y quién no fue objeto de polémica, pues al usar la metodología de NBI se soslayó el acceso a servicios comunales o la historia de cómo se había perdido el acceso a servicios clave: hasta la década de 1980 era común que las empresas dotaran a las familias de los trabajadores de envases con agua, kerosene y que corrieran con todos los gastos de electrificación.

En todo caso, la situación de precariedad de gran parte de las viviendas o la falta de servicios es atribuida por un sector de los morocochanos a la (ir)responsabilidad personal de quienes en ellas vivían. Una entrevistada, por ejemplo, comentaba cómo ella, a pesar de haberse instalado en una zona de reciente ocupación, rápidamente conectó su vivienda al sistema de agua. Para ella, las personas que no tenían estos 
servicios en sus casas así lo querían por "dejados», haciendo eco del discurso del involucramiento que analizamos líneas arriba. Según su parecer, los nuevos vecinos de Morococha llegaban con una visión cortoplacista: llegar, trabajar e irse. Así pues, su interés no estaría en mejorar sus casas o vivir propiamente. La informante, como antigua vecina, además, veía cómo la población fluctuaba rápidamente: algunas personas llegaban y se quedaban por unos meses, otros por años e incluso décadas. Esta diferencia se manifiesta, entonces, en las construcciones del distrito, así como en la materialidad de las viviendas: los más antiguos disponían de viviendas mejor construidas y equipadas, mientras que los temporales se acogían en casas más precarias o en cuartos alquilados en las casas del pueblo o en los campamentos.

El estudio de línea de base dio una imagen estática de la situación económica y social del distrito, pues si bien registró la precariedad de buena parte de la ciudad, no reparó en los motivos de esta, como la dinámica poblacional y migratoria o la precarización del empleo y la consiguiente desestabilización de los trabajadores. La pobreza fue expuesta como un hecho consustancial a la población, cuya solución pasaba por destruir el asentamiento para brindarles mejoras infraestructurales en un nuevo espacio. No hubo reflexión sobre, por ejemplo, el efecto de la reducción de costos en áreas clave como bienestar obrero, en la situación de las viviendas o en el corte de la provisión de servicios, que poco a poco fue menguando tras la privatización de Centromin.

Por su parte, el Estado peruano intervino a través de Defensa Civil y otras entidades para disuadir a los pobladores de quedarse en sus viviendas de Morococha. El 25 de agosto de 2013 se declaró el estado de emergencia por un periodo de sesenta días. El motivo fue el "peligro inminente de movimiento en masa», y el objetivo, ejecutar las acciones requeridas para la «reducción y minimización del alto riesgo existente en la zona afectada» (Instituto Nacional de Defensa Civil, 2014, p. 1) mediante la reubicación de la población. Un mes más tarde, se publicó la ley 30081, mediante la cual se cambió la ubicación geográfica de la capital de distrito hacia la llamada «Nueva Morococha». Pasados los sesenta días del estado de emergencia, este se extendió por un segundo período de igual duración. La Nochebuena de ese mismo año, se prorrogó por un tercer período.

Durante la segunda declaratoria de emergencia se formó una mesa de trabajo cuyo fin fue planificar y supervisar la evacuación de Morococha. Esta mesa tuvo como miembros a representantes del Gobierno Regional de Junín, de la fiscalía de la provincia de Yauli, las direcciones regionales de Salud, Educación y Vivienda, la Oficina de Gestión de Conflictos de la PCM, la municipalidad distrital y provincial, Defensoría del Pueblo y la empresa eléctrica Electrocentro. Entre las primeras medidas tomadas estuvo trasladar a las instituciones públicas hacia la nueva ciudad, para lo cual Chinalco entregó la infraestructura municipal a las autoridades. Asimismo, se 
estableció un cronograma de transferencia de las instalaciones que faltaban, como estadio, mercado, terminal terrestre y centro cultural. Al mismo tiempo, se envió un grupo de inspectores técnicos de seguridad del Gobierno regional con la misión, aparentemente preestablecida, de verificar el riesgo y declarar inhabitable el espacio (Instituto Nacional de Defensa Civil, 2014, p. 3).

En los meses finales de 2013 quedaban en Morococha 396 familias, de las cuales solo 231 tenían la posibilidad de acceder a viviendas en la nueva ciudad. Se decidió trasladar temporalmente al resto hacia locales públicos, tales como el coliseo o el museo. A inicios de 2014, el Gobierno regional envió ayuda humanitaria al distrito que fue usada para la implementación de albergues temporales en Carhuacoto. En febrero de ese año, se instaló una mesa de diálogo para sensibilizar a la población que continuaba residiendo en Morococha (Instituto Nacional de Defensa Civil, 2014, p. 5). El 20 de febrero se suspendió el servicio de energía eléctrica en Morococha. Durante las semanas siguientes se siguió discutiendo el tema de la construcción de albergues temporales, así como las coordinaciones para el traslado de las instituciones públicas, como colegios y escuelas, gobernación distrital, comisaría y posta médica.

La inhabitabilidad de Morococha, producida por una combinación de factores naturales y decisiones del gobierno, fue enfatizada como nunca antes y el riesgo geológico en la zona se volvió repentinamente un tema de interés para el Estado. Zeiderman (2012) ha explorado la emergencia del factor riesgo como una técnica de planeamiento y gobernanza urbana. Si bien su estudio se enmarca en el desarrollo de asentamientos informales en las periferias de Bogotá, su enfoque no es útil para analizar la actuación del Estado peruano. Según la explicación tradicional, la migración campo-ciudad ejerció presión sobre la oferta de vivienda urbana, relegando a los nuevos migrantes a las colinas del sur de la ciudad. Estas tierras habían sido deforestadas y explotadas como canteras para material de construcción de los distritos centrales. Tras extraer todo el valor de las colinas, aparecieron urbanizadores piratas que las parcelaron y vendieron. Según esta narrativa, los asentamientos de migrantes pobres estuvieron condenados a quedar expuestos al riesgo desde un inicio. Para Zeiderman, este tipo de explicación explora críticamente los procesos demográficos, económicos y geográficos de producción del espacio urbano y de desigualdad ambiental; sin embargo, olvida historizar la categoría de "zona de alto riesgo» (Zeiderman, 2012, p. 1571). El riesgo aparece de este modo como una característica física inherente al paisaje urbano, antecediendo a los estudios, mapas y planos que produjeron el riesgo como técnica de gobierno. Asimismo, si bien esta narrativa considera el riesgo como una carga injusta puesta sobre los pobres, es insuficiente, pues estas zonas de riesgo, con los mismos factores que lo produjeron, ahora se usan para justificar su eliminación y la reubicación de sus habitantes. El riesgo es así convertido en el motor de una lógica del desplazamiento (Zeiderman, 2012, pp. 1571-1572). 
En el caso bogotano, el riesgo emerge de manera dinámica y negociada a lo largo del mapeo elaborado por los peritos con participación de los vecinos que, desde sus propias categorías y juicios, deciden enseñar —o no grietas - y desniveles en el suelo para que luego sean examinadas por los inspectores. Así, las zonas de riesgo se expanden o contraen a partir de la continua negociación entre actores. El riesgo no emerge por sí solo, como una serie de bordes inertes que designan un espacio de intervención (Zeiderman, 2012, p. 1586).

Dado el carácter del espacio sobre el que se mapeó el riesgo: urbano, en plena capital y con una población creciente, este se produce de manera dinámica y negociada, por sectores y progresivamente. En Morococha, la producción del riesgo, en cambio, fue impositiva, pintando de un brochazo el espacio entero bajo presión de la empresa y el Estado para fomentar la evacuación preventiva del área.

En Morococha el riesgo fue usado como un recurso para forzar la salida de quienes se resistían a abandonar sus hogares. En el contexto de conflicto que caracterizó al distrito durante esos años, no era difícil sospechar de las razones de Estado. La desconfianza hacía a muchos pensar que el dispositivo de riesgo era en realidad un artificio para deslegitimar a los que permanecían en Morococha. Los argumentos usados por Defensa Civil tenían una verosímil base empírica: fuerte erosión de los suelos debido a los químicos de los relaves, decenas de túneles excavados por debajo de centro urbano durante más de un siglo de actividad minera, etc. Sin embargo, al privilegiar un discurso exclusivamente técnico, se redujo el problema a una cuestión de peligro físico. Esta situación fue abordada en términos de "ayuda humanitaria», cuando se trataba más bien de un asunto político de desacuerdo en los términos de la negociación para el reasentamiento. Como en otros casos globales, la estrategia de despolitización (Ferguson, 1994) de los proyectos de desarrollo se ha vuelto parte del repertorio tanto de las empresas como del Estado, al involucrarse en procesos de reasentamiento (Salas, 2008).

\section{LOS EJES DE DERECHO A LA VIVIENDA Y LOS CONTORNOS DE LA COMUNIDAD}

Ballard y Banks (2003) han señalado la emergencia de la comunidad local como un actor relevante en la "guerra por los recursos» como un rasgo importante en la problemática minera de las últimas décadas. En el contexto peruano, esto ha significado un declive de la organización sindical como plataforma de lucha y el posicionamiento de la comunidad campesina como interlocutor de las negociaciones. Este cambio se hace notorio, además de la ubicua presencia mediática de imágenes de campesinos movilizados, a través de la atenuación social de los contratos laborales de los sindicatos. En la época de fortaleza sindical, los contratos laborales eran negociados tomando en cuenta los pliegos de reclamo, cuyos contenidos incluso 
excedían el ámbito estrictamente laboral para incluir medidas específicas como la mejora de la infraestructura del campamento y beneficios para las familias. Frente al estrecho margen de negociación de los trabajadores en la actualidad, se percibe una densificación social de los convenios comunidad-empresa (Helfgott, 2017).

Este «trasvase de lo social» desde la relación laboral hacia una relación por la tierra se da fundamentalmente con comunidades campesinas que tienen distintos grados de tenencia y propiedad. En cambio, en Morococha podríamos utilizar el concepto de «relación por lugar», puesto que no existe propiedad colectiva, y lo que se moviliza es más bien un sentido de pertenencia e identidad no siempre compartido. Esto abre las puertas a analizar el conflicto mediante una doble ausencia: mientras que para las instancias de conflicto minero-campesino lo social toma cuerpo mediante la invocación de derechos comunales, para Morococha la base espacial que da sustento las formas de comunidad ha sido carcomida por el reasentamiento.

El año 2012 fue clave en la historia reciente de Morococha, pues marcó el momento en que las divisiones sociales se hicieron visibles de manera concreta mediante la separación espacial de la población. Un tema crítico — que no fue tomado en cuenta durante el proceso de reasentamiento- fue reconocer la estratificación y diferencias entre los habitantes del distrito. Estas diferencias se pueden resumir en dos: de clase y de vinculación con el lugar.

Existen varias dimensiones que se entrecruzan para determinar el nivel de legitimidad que tiene una persona al reclamar derechos durante el reasentamiento. Estas tienen que ver con el tiempo de residencia, la reivindicación de autoctonía y el estatus legal de la vivienda. Así, surgen tres oposiciones: venido/nacido, inquilino/ propietario y no residente/residente. Estas, sin embargo, hacen referencia a puntos extremos de una gradiente, pues en el caso de la propiedad, como hemos visto, los títulos no se encontraban claros. Asimismo, el reclamo de autoctonía es difícilmente sostenible en un espacio caracterizado por la migración y el trabajo temporal. Los ejes que menciono han servido como líneas que dibujan en cierto modo el sentido de comunidad, definiendo los límites dentro de los cuales se inscribe la pertenencia y, por tanto, el derecho a la vivienda. No debemos olvidar, claro, que estos ejes están implícitamente politizados en el contexto de reasentamiento e incluso desde antes de esta coyuntura: tienen que ver con trayectorias de vida, lugar de origen, rivalidades políticas, poder adquisitivo, estatus social, etc. Es importante, igualmente, señalar que aquellos que más énfasis pusieron en resaltar la importancia de establecer una distinción en función de criterios de propiedad fueron en su mayoría ex propietarios o personas que han sentido que su situación ha empeorado como consecuencia de ignorar la distinción social.

La primera oposición (venido/nacido) está presente de manera recurrente en el discurso de los afectados por el reasentamiento. Morococha, por su carácter de lugar 
de llegada para mineros, no resulta ser el lugar de nacimiento de buena parte de sus residentes: por lo general, estos han venido de otro pueblo y se han establecido en Morococha temporalmente. En otros casos, resultan ser hijos de antiguos trabajadores que decidieron permanecer en la ciudad aun después de haber dejado su empleo en alguna de las empresas mineras. Estos últimos son los nacidos, quienes suelen tener un mayor apego al distrito pues representa su pueblo, en oposición a aquellos venidos durante tiempos de crisis que pudieron haber partido hacia otro lugar. La situación de los nacidos es crítica, pues tras el reasentamiento existe una ansiedad generalizada de que Morococha podría eventualmente convertirse en un pueblo fantasma y desaparecer por completo. De ser así, habrían perdido mucho más que una fuente de empleo o activos económicos. Se trataría de una pérdida mucho más fundamental: de identidad, historia y pertenencia.

Entre los venidos encontramos a aquellas personas que llegaron ya en edad adulta y no necesariamente tienen un vínculo de autoctonía con el distrito. Esta categoría resulta, sin embargo, problemática, pues si bien un residente puede no haber nacido en Morococha, una larga residencia puede hacer que este sea visto en la práctica como alguien autóctono. El tema de la autoctonía, como dije, tiene que ver con una cuestión identitaria, que, si bien no depende exclusivamente de haber nacido o haber venido, resulta de importancia capital para establecer la trayectoria de una persona y su relación con la ciudad y el distrito. Un profesor de escuela de aproximadamente 60 ańos, antiguo trabajador minero y con una larga trayectoria pública en Morococha, expone la relación entre identidad, origen y residencia de la siguiente manera:

Somos producto del enganche de los mineros que llegan unos solos y otros con sus familias y así van formando el pueblo. $\mathrm{Y}$ entonces las pocas generaciones llegan a formar ese pueblo, constituyen ese pueblo, pero ya muchos de ellos fallecidos, y los hijos salen. Pero entonces, ¿quién[es] lo constituyen el pueblo y su identidad? Son los mineros que deciden quedarse a trabajar en Morococha. Muchos viven allí y otros por la misma necesidad de seguir superándose llevan a sus hijos a otro sitio. Entonces el pueblo lo llegan a formar ellos de nuestros ancestros sus generaciones que quedan, como es el caso mío. [...] Entonces el pueblo lo conformamos, yo diría, hasta el último personaje que llega a Morococha, pero quiere involucrarse [...]. Entonces ellos llegan a formar este distrito minero que es un pueblo propio, que su identidad es más minera, porque muchos de ellos han traído otra identidad de sus pueblos, sus costumbres, por ejemplo. O como ocurre por ejemplo en Acolla, cuando ya se jubilaban los hombres van a su pueblo, a su terruño, regresan, y entonces escuchan una música y dicen «bailaba en Morococha» [...]. Vienen de diferentes lugares, forman familia, pero regresan. Pero ellos, pues, esa identidad minera queda cuando hacen una propiedad, cuando deciden apostar por el pueblo con una casa. ${ }^{4}$

4 Entrevista realizada por el autor. Morococha, 10 de septiembre 2015. 
Un segundo elemento que emerge es el de la propiedad, que como explica el profesor, es un indicador del involucramiento de una persona con el pueblo; de ese modo, la progresión ideal es trabajo $\rightarrow$ familia $\rightarrow$ propiedad $\rightarrow$ pueblo. El ser propietario revela el nivel más alto de involucramiento de un individuo con el pueblo: la casa marca su presencia e intención de hacerla permanente y formar parte de la comunidad. Para el profesor, la progresión que hemos señalado existía en el pasado, gracias a una relativa estabilidad laboral. En los últimos años, y en especial con el contexto del reasentamiento muchos de los que llegaron tuvieron otra intención. Como indica luego el profesor: «Hay gente que vino y no se involucró, solo se benefició, ni siquiera trajo su costumbre para dejarnos, sino se llevó todo ello, porque solo vino a lucrarse». En ese sentido, existen dos tipos de venidos: aquellos que se involucran y aquellos que no.

La oposición inquilino/propietario marcó el carácter del conflicto durante los primeros momentos del proceso de reasentamiento. Si bien los títulos de propiedad nunca estuvieron «en orden» - la propiedad del suelo era de la empresa y luego de la municipalidad, los intentos por realizar un catastro fueron frustrados, no hubo voluntad por legalizarlos antes, entre otros motivos-, el estatus de "propietario" surgió como un elemento de distinción que buscaba que aquellos que se incluían dentro de esa categoría reclamen mayores beneficios que un inquilino. Para explicar este punto es necesario volver a la formación de la Asociación de Vivienda Morococha (AVM), comentada líneas arriba. Según la versión de un dirigente de esta asociación, entre 2004 y 2005, un grupo de propietarios mostró su disconformidad ante el prospecto de que los inquilinos recibieran viviendas en la nueva ciudad.

El argumento para ello fue negar que los no-propietarios pudieran considerarse morocochanos. Para el dirigente, la intransigencia de este grupo reveló que existín intereses económicos, pues los propietarios recibían rentas de aquellos a quienes intentaban negar el derecho a la vivienda. La AVM aparece en este contexto como una forma de defender su derecho a vivienda. Según sigue el relato, al grupo de propietarios la empresa Perú Copper les ofreció comprarles sus terrenos y viviendas y facilitarles una reubicación individual en cualquier parte del país. Frente la posibilidad de una disgregación de la población y desaparición del pueblo como efecto de esa política soterrada, un grupo de residentes preocupados por la vigencia histórica de Morococha presionaron para realizar el traslado de manera colectiva. La AVM recogió esta preocupación y la incorporó en sus demandas.

Pero, ¿cómo emerge esta división entre «propietarios» e «inquilinos» en un cuasi territorio empresarial, cuya dinámica social se manejaba a modo de institución total ${ }^{5}$ ?

\footnotetext{
El término es del sociólogo Erving Goffman, quien lo usa para definir aquellos lugares de residencia y trabajo en los que se concentran grandes números de personas en similar condición social
} 
Una de las funciones de la organización del espacio en las ciudades-campamento es la ubicación del individuo en el entramado social de la comunidad. La división de los barrios en campamentos, por un lado, y «distrito", por otro, nos informa sobre la manera en que dos grandes grupos habitaron la ciudad de Morococha.

Los campamentos en pie antes del reasentamiento fueron, en su mayoría, construidos a partir de la década de 1970 para albergar a los obreros que llegaban a trabajar en los socavones. La práctica existió desde antes, aunque con Centromin se volvió una política generalizada. Además de Centromin y la Cerro — las dos operadoras principales-, coexistieron con ellas otras empresas como Santa Rita, Centraminas y Austria Duvaz, esta última con una historia de más de cien años de operación continua en el distrito. Además de "Morococha Nueva» y «Morococha Antigua», a veces se menciona el sector «Duvaz» como una tercera división de la ciudad. Centromin heredó los campamentos de la Cerro de Pasco e instaló ahí a sus trabajadores, además de levantar una serie de campamentos adicionales en los barrios de Natividad y Cajoncillo. Las empresas más pequeñas también tenían sus propios campamentos, algunas en plena ciudad y otras en zonas más alejadas, como el sector conocido como Manuelita. En ellos vivían los obreros con sus familias, lo que indica que estos no eran solo refugios temporales entre las horas de trabajo, sino más bien hogares en toda la magnitud de su significado.

En oposición a los campamentos, el núcleo urbano de la ciudad agrupa viviendas construidas de manera individual por funcionarios públicos, maestros de las escuelas y colegios de las empresas, y posteriormente fiscales o hijos de antiguos mineros que pasaron afincarse en la ciudad. Algunos trabajadores contratados, asimismo, llegaron a construir sus propias casas fuera de los campamentos.

Esta división se refleja en la disputa por el derecho a vivienda entre los propietarios y los inquilinos. Es posible mapear diferencias de clase en la distribución del espacio: obreros en los campamentos y empleados en la ciudad. Aunque separados, no existía una segregación entre ambos espacios, a diferencia con lo que ocurría en el campamento-club de Tucto, donde residían los funcionarios extranjeros o de alto nivel. El flujo entre campamentos y ciudad era fluido y, aunque existía control en la entrada a las zonas de vivienda, el tránsito no estaba restringido. La categoría de propietarios es usada en Morococha para englobar a las personas que podían reclamar un predio como suyo a partir de un título de propiedad o como «posesionarios de buena fe». En realidad, la entidad que mantuvo la propiedad de

que comparten la vida cotidiana regulada de manera formal (Goffman, 1970, p. 13). Goffman aplica el concepto a instituciones como las prisiones y los hospitales psiquiátricos, resaltando el aislamiento al que son sometidos los internos. En el caso de los campamentos mineros, el aislamiento no ocurre necesariamente en términos de encierro: la ubicación de las minas suele estar en puntos alejados, dando lugar a dinámicas sociales similares. 
los terrenos fue durante muchos años la municipalidad y Centromin que, tras su privatización, donó alrededor de 34 hectáreas que aún mantenía a su nombre a la autoridad local. Algunas de las familias que habían tenido a un miembro trabajando en la empresa estatal siguieron viviendo en aquellos campamentos ubicados en las tierras donadas.

Los propietarios residían en la ciudad, es decir, aquellos barrios en donde fueron las propias familias las que edificaron sus viviendas siguiendo patrones típicos de otros pueblos andinos y usando materiales como el adobe y la tapia. A partir de la década de 1990, sin embargo, esta tendencia al uso de material de tierra fue reemplazada por el material noble y prefabricado. Los trabajadores, por otro lado, vivían en los campamentos o, crecientemente como inquilinos en las viviendas del distrito. Según el número de años y el tamaño de su familia, un trabajador podía acceder a viviendas de campamento más grandes, si es que la empresa lo concedía, o adquirir un terreno y construirse una casa propia. Los inquilinos, asimismo, podían ser también miembros de familias propietarias que, habiendo alcanzado cierta edad y establecido un núcleo familiar separado, alquilaban parte de las grandes casas de la ciudad para sí mismos.

En el año 2005 intervino la consultora SCG con la intención de hacer del proceso de reasentamiento un "proyecto de desarrollo", en cumplimiento de las directivas internacionales sobre reasentamiento poblacional (Cernea, 1988, p. 45). La llegada de SCG avivó la polémica entre propietarios e inquilinos pues un grupo de opositores al reasentamiento empezó a argumentar que la AVM no era más que una «invención de Chinalco» para dividir a la población y así conseguir sus objetivos más fácilmente. Existe hasta ahora una tensión muy fuerte, aunque velada, entre los inquilinos y los propietarios, pues estos últimos consideran que fueron traicionados por los primeros, transando con la empresa para beneficiarse en detrimento del bien común.

El malestar de los propietarios con los inquilinos se articula con el discurso del involucramiento con el pueblo. El ejemplo más claro es el caso de un grupo de personas que se instaló en Morococha alrededor del año 2005, cuando ya era conocido el complejo proceso que la ciudad afrontaría. El efecto que tuvieron los inquilinos "peregrinos», en contraposición a los inquilinos residentes, fue - bajo esta óptica - crear un grupo de avanzada que aceptó trasladarse complacientemente, debilitando al grupo que deseaba mantener una posición fuerte en la negociación. Por otra parte, la súbita y reciente llegada de aquellos nuevos residentes en el distrito generó distorsiones en el tejido social de Morococha, pues estos componen actualmente buena parte de la población de la nueva ciudad. Para los antiguos residentes de Morococha, la nueva ciudad está llena de «desconocidos», fenómeno que tiene que ver no solo con la llegada de nuevos residentes durante el reasentamiento, sino 
también con lo ocurrido una vez otorgadas las nuevas viviendas. Luego del año 2012, muchas de las personas que recibieron su casa en la nueva ciudad decidieron mudarse a otro sitio y alquilar sus propiedades a terceros. «Entonces, toda la gente que vivía arriba ya se ha ido, han dejado alquilada sus casas a esa gente desconocida», afirma una joven madre (35 años) sobre el tema.

Esta última constatación nos lleva a la tercera y última de las oposiciones identificadas en el trabajo de campo: la de no residentes/residentes. Si bien los nacidos en Morococha tendrían una cierta legitimidad en cuanto a sus reclamos por beneficios, aquellos que permanecen en el distrito muestran distintos grados de disconformidad con aquellos que emigraron de Morococha y pretendieron obtener una vivienda en la nueva ciudad. Esto queda claro en la participación de un dirigente en una asamblea informativa convocada por el alcalde tras una reunión de la Mesa de Diálogo en Huancayo, quien dice que "hay dos tipos de morocochanos: los que se quedan arriba valientemente y los que bajaron bajo su propia responsabilidad y decisión». El llamado a la unión es claro: es morocochano el que está en Morococha, independientemente de si nació o no ahí. La pertenencia a la comunidad se forja partir de la permanencia en el lugar. Esta afirmación pierde algo de peso si prestamos atención a la lista de asociaciones civiles que participan del proceso de diálogo y notamos la participación de grupos de ex residentes o «hijos de Morococha» en Huancayo o Lima.

Dependiendo de a quién se le pregunte, las respuestas sobre la pertinencia de que personas que ya no viven en Morococha accedan a una indemnización varían. Están aquellos que piensan que los ex residentes no tienen derecho a reclamo, así como los que matizan su opinión según el grado de contacto que mantengan con el distrito hasta la actualidad a través de familiares o propiedades.

Por otro lado, hay quienes no ven con malos ojos la presencia de nuevas personas, pero con la condición de que permanezcan, que se vuelvan residentes. Un ejemplo de este deseo es la respuesta que me dio una madre de familia de aproximadamente 50 ańos sobre si un trabajador temporal y sin familia debía acceder a una vivienda en la nueva ciudad:

Con el compromiso de que su familia viva aquí, sí. Pero ¿qué han hecho muchos? Recibieron la casa, recibieron su bono y se fueron. Otros recibieron la casa, lo alquilan y se fueron. Que no viven su familia aquí. Como muchos otros como que vienen, a veces me comentan «yo ya me voy ya, ya este ańo estuve, pero ya me voy». Cuando te dicen así, te quiebran. Porque a veces se van, menos gente, ya aquí ya no tenemos campamentos. [...] la gente tiene esa idea ahorita, «[a] fin de año ya nos vamos, qué vamos a hacer acá», la casa no les costó, les regalaron $[. .$. Otros, que han entrado a Chinalco, dicen: «no pe ya mi esposo está en Chinalco, casi no lo veo, mejor me voy, qué hago acá, ¿no? Y cuando sale igual va a venir a 
verme. Entonces me voy». Esa es la perspectiva de la gente ahora: ¿y qué hacemos los que vivimos aquí, los que somos de aquí, los que no tenemos otro sitio dónde ir? De esos hay pocos, Chinalco debió preferir a esos, pues. No digo que no para todos, cuando hay que haiga para todos acá, qué tengo que mezquinar, pero que debió haber preferido a la gente que es oriunda de ahí, que tiene muchos años ahí. Que tiene, pues, sus raíces ahí. ¿A dónde va a ir esa gente? Esa gente se merece, no solo se merece, se necesita que se les solucione, porque es su tierra, pero la gente que no es su tierra, igual pues se van a su pueblo y ya. Solucionado. Hay mucha gente que no le importa. Hay mucha gente que [...] «yo mentira me peleo, si no hay trabajo también ya me voy a mi tierra, me voy a mi chacra», dice. Yo alguna vez le dije a uno "qué bueno que tengas pueblo, pero los que estamos de acá, los que este es nuestro pueblo, no tenemos qué [comer]». Ellos lo tienen solucionado, ¿pero nosotros? Somos poquitos, pero estamos, pues. ${ }^{6}$

El pasaje citado muestra la forma en que se entremezcla el discurso de autoctonía con el de residencia, pues si bien algunos morocochanos nacidos han podido establecerse fuera del distrito, otros han tenido que quedarse por diferentes motivos. Estos últimos serían los que más urgentemente requerirían una solución. A pesar de que se establece una distinción con respecto a los inquilinos o residentes recientes, estos no están excluidos de la comunidad en su conjunto. pueden reclamar y beneficiarse, siempre y cuando prime el derecho de los oriundos, aquellos que no pueden recurrir a otro pueblo.

\section{Conclusiones}

La particularidad del reasentamiento de Morococha reside en la dinámica social determinada por las necesidades laborales de las empresas mineras. A lo largo de este artículo se ha explorado el trasfondo cultural y político, así como los términos en los que se organizan las diferencias sociales a partir de dicotomías que ubican a las personas en el entramado de la comunidad local. Asimismo, se ha analizado los discursos técnicos mediante los cuales se justificó la necesidad del reasentamiento.

En un contexto de cambios en la industria minera en el Perú, resulta interesante analizar la manera en que la empresa y el Estado han llevado adelante uno de los procesos de reasentamiento de mayor envergadura en la historia reciente. El proceso fue racionalizado por los actores responsables como una intervención cuasi humanitaria, enmarcada normativamente por las directivas del Banco Mundial (2004, p. xxviii) sobre reasentamiento involuntario. Esta voluntad de mejorar se intercala, e incluso confunde por momentos, con los discursos de Responsabilidad Social Corporativa y relacionamiento comunitario, dando lugar a una economía moral (Scott,

6 Entrevista realizada por el autor. Morococha, 8 de octubre 2015. 
1977; Himley, 2012, p. 402) enfocada en el «fortalecimiento de capacidades» individuales orientadas a actividades externas a la economía política del modelo de campamento. Estas prácticas, englobadas en lo que venimos a conceptualizar bajo la noción de gubernamentalidad neoliberal, cuyos mecanismos de intervención en lo social coproducen formas de comunidad y subjetividad (Van Teijlingen, 2016) que entran en tensión entre sí. Simultáneamente, la gubernamentalidad corporativa en Morococha procura reducir la capacidad de resistencia y negociación de los afectados al menoscabar discursivamente las bases del desacuerdo. Mediante la designación de los reasentados como pobres vulnerables al riesgo geológico, la empresa intentó enmarcar su agencia dentro de la práctica del desarrollo, como receptores de ayuda o «beneficiarios» de un proyecto de desarrollo. En ese sentido, la principal estrategia corporativa, similar a otros casos recientes, fue la despolitización el reasentamiento, apelando al discurso del desarrollo (De la Puente, 2015; Ferguson, 1994). Sin embargo, la actualidad nos muestra cómo estas estrategias de despolitización son proyectos inacabados e imperfectos: lo político se desplaza desde las relaciones laborales hacia las comunitarias.

Las páginas anteriores han demostrado cómo el reasentamiento de Morococha requirió para su puesta en marcha la definición de un conjunto de «beneficiarios» del proyecto de reasentamiento a partir de ciertas características seleccionadas por la empresa minera que terminaron por aplanar la estratificación social del lugar, dando como resultado una imagen de la población indistintamente pobre y amenazada, en contraposición a la diversidad expuesta por los testimonios etnográficos, que revelan una historia mucho más compleja. El sujeto social de Morococha, construido históricamente a partir de vínculos con el proceso productivo y el involucramiento con los vecinos, se aleja de la imagen estática y dócil pergeñada por Chinalco.

En este intento de despolitización del proceso de reasentamiento, se percibe asimismo una reconfiguración de las relaciones sociales de producción en el contexto minero. Estos cambios suceden, fundamentalmente, por la generalización de las contratas y la progresiva desvinculación de los trabajadores con respecto a las empresas a las que prestan servicio. En contraste con la situación de la minería «tradicional», en la actualidad los trabajadores ya no establecen vínculos fuertes con las mineras ni con el entorno en el que se desempeñan. Si en el pasado las dinámicas sociales de la industria llevaban a la formación de núcleos urbanizados en los que la política del trabajo, la sindicalización y las luchas sociales eran el pan de cada día, en la actualidad puede notarse un cierto grado de despolitización del entorno urbano de Morococha en un contexto de flexibilización laboral ${ }^{7}$. Ahora bien, esta estrategia

7 El sociólogo Omar Manky (2017) identifica hasta tres formas de acción colectiva relacionadas
con distintos tipos de movilidad espacial. Según su modelo, Morococha habría pasado de un modelo 
corporativa se ve confrontada por otro proceso que repolitiza el espacio. La ciudad, otrora escenario de conflicto, se convierte en Carhuacoto en objeto del conflicto.

Si bien afirmo que el espacio se ha convertido en el contexto del reasentamiento en objeto de conflicto — es decir, en una política de lugar-, la política sigue sucediendo en el lugar. Como objeto, la producción de la nueva ciudad (Lefebvre, 1991) surge principalmente como efecto de las decisiones de los especialistas contratados por Chinalco para desarrollar un entorno urbano planificado que cumpla con los requisitos internacionales y ciertos preceptos de funcionalidad —el tamańo de viviendas, el trazo de las avenidas y calles, la ubicación de los servicios públicos, etc. - y, en buena parte, de una impresión estética de orden. En ese sentido, se trata de una producción del espacio hecha para el espectador externo, para la sociedad nacional que requiere muestras del progreso de la minería moderna. En palabras del vicepresidente de Asuntos Ambientales y Corporativos de Chinalco Perú, a las familias reasentadas se les ha dado un "trato espectacular» ${ }^{8}$.

Las justificaciones brindadas por el Estado y Chinalco coinciden en no historizar el riesgo ni la pobreza. La intervención del Estado sobre el riesgo en el distrito se dio de manera despolitizada y ahistórica, pues no se exploraron los procesos que llevaron al asentamiento de personas en áreas vulnerables, al mismo tiempo que se naturaliza la posición vulnerable. En ese sentido, puede decirse que las sospechas de los morocochanos son comprensibles en tanto el discurso tecnificante de la empresa (Murray Li, 2007, cap. 4) y del Estado borra los conflictos históricos subyacentes en la producción del espacio en Morococha. Mediante el dispositivo de riesgo y el discurso de pobreza, el Estado y Chinalco intentaron con distinto grado de éxito construir un sujeto de reasentamiento despolitizado y susceptible de ser desplazados con la promesa de un desarrollo en otra parte.

Por su parte, una "población excedente» (Murray Li, 2017, p. 1249), de limitada relevancia para el capital y la industria, enfrenta una política de distribución de «beneficios» de corte neoliberal mediante repertorios limitados resultantes de su particular experiencia histórica. Resulta esperable que, en un contexto de fragmentación social y de incertidumbre ante el futuro, la población recurra a mecanismos individuales de reclamo de derechos basados en la pertenencia. Como afirman Smith y Helfgott (2010, p. 22), el silenciamiento de los conflictos laborales ha desplazado la atención hacia asuntos de relaciones basadas en el sentido de lugar. Tal es el caso de la comunidad campesina de Huallay (Pasco), analizado por Helfgott

de ciudad a uno de hotel minero, en el que la lógica de acción política estaría delimitada por redes de apoyo externas a la comunidad local.

8 Hundreds in Peru Balk at Relocation From Site of Mine. The New York Times, 6/1/2013. https:// www.nytimes.com/2013/01/07/world/americas/hundreds-in-peru-balk-at-relocating-from-coppermine-site.html 
(2013), o de la resistencia indígena en la comunidad de Angaraes (Huancavelica) estudiada por Durand (2010), ambas con larga tradición minera, en las que lo social persiste bajo otra forma. En contraste, en Morococha la posibilidad de procesos análogos a estos fueron forcluidos por el reasentamiento. Sin un lugar al que apelar en común, la conformación de una plataforma compartida fue truncada. La implosión del conjunto social en los tres ejes analizados demuestra la dificultad por articular un reclamo comunitario, limitando la acción colectiva a la agregación de trayectorias individuales que justifiquen el derecho legítimo a una compensación ante la empresa minera.

La irónica preocupación por la búsqueda del autochthon (nacido de la tierra) en un asentamiento de migrantes y la definición del «verdadero morocochano» con derecho a compensación se explica por la ansiedad de encontrarse con una coyuntura en que el círculo de quiénes están adentro y quiénes afuera de la economía de neoenclave (Himley, 2012, p. 396) se hace cada vez más estrecho (Geschiere, 2012, p. 55) por criterios impuestos desde una lógica de gobierno corporativo que busca desembarazarse de "cargas sociales» (Smith y Helfgott, 2010, p. 22). Para Zawada (2010), quien estudió la gubernamentalidad corporativa en Nigeria, los actores privados se valen de técnicas de gobierno basados en discursos de responsabilidad individual y autosuficiencia que las descargan de obligaciones hacia la comunidad (Himley, 2012, p. 404), aun a pesar de la grandilocuente etiqueta de Responsabilidad Social Corporativa que estampan a sus intervenciones.

El desfase entre la imagen plana marcada por la doble amenaza de pobreza/ riesgo geológico y la rica y compleja historia de la constitución de la comunidad local termina por jugar en contra de los intereses de la empresa, ya que, hasta el momento, no se ha logrado dar por finalizado el proceso de reasentamiento de Morococha, donde el descontento y el malestar crecen día a día?

\section{REFERENCIAS}

Aranda, E. (1997). Talara: la imagen trizada de un proyecto de ciudad moderna. Debates en Sociología, 22, 169-191.

Aranda, E. (1998). Del proyecto urbano moderno a la imagen trizada. Talara: 1950-1990. Lima: PUCP, UNI.

\footnotetext{
9 A la fecha, la ampliación de la mina hacia un sector de la ciudad parece estar en riesgo por la decisión de la Corte Superior de Justicia de Junín de paralizar las obras para evitar la destrucción del ornato urbano de un sector aún habitado por 65 familias. Ver «Toromocho: ¿está su ampliación en riesgo?». El Comercio, 4/2/2019. https:/elcomercio.pe/economia/dia-1/ toromocho-ampliacion-riesgo-chinalco-peru-inversion-minera-mineria-junin-noticia-604031
} 
Aranda, E. (2009). Construcción social del espacio y vida cotidiana en los campamentos de La Oroya y Talara: 1900-1960. Investigaciones en Ciudad \& Arquitectura, 2(2), 51-62. Ballard, C. y Banks, G. (2003). Resources Wars: The Anthropology of Mining. Annual Review of Anthropology, 32, 287-313. https://doi.org/10.1146/annurev. anthro.32.061002.093116

Banco Mundial (2004). Involuntary Resettlement Sourcebook: Planning and Implementation in Development Projects. Washington D.C.: World Bank.

Bebbington, A., Humphreys, D., Bury, J., Lingan, J., Muñoz, J.P. y Scurrah, M. (2011). Los movimientos sociales frente a la minería: disputando el desarrollo territorial andino. En J. Bengoa (ed.), Territorios rurales. Movimientos sociales y desarrollo territorial rural en América Latina (pp. 283-315). Santiago de Chile: Editorial Catalonia.

Bulmer, M. I. (1975). Sociological models of mining community. The Sociological Review, 23(1), 61-92. https://doi.org/10.1111/j.1467-954X.1975.tb00518.x

Burga, M. y Flores Galindo, A. (1991[1980]). Apogeo y crisis de la República Aristocrática. Lima: Rikchay Perú.

Cernea, M. (1988). Involuntary Resettlement and Development. Finance \& Development, 25(3), 44-46. https://doi.org/10.1596/0-8213-1036-4

Chuquimantari, C. (1992). Yauli-La Oroya: Minería y ciudades empresas. La Oroya: Asociación Laboral para el Desarrollo.

Contreras, C. y Hernández, E. (eds.) (2017). Historia económica del norte peruano. Señoríos, haciendas y minas en el espacio regional. Lima: IEP, Banco Central de Reserva del Perú.

Contreras, C. y Cueto, M. (2013). Historia del Perú contemporáneo. Desde las luchas por la Independencia hasta el presente. Lima: IEP, PUCP, CIUP.

De Echave, J., Diez, A., Huber, L., Revesz, B., Lanata, R. y Tanaka, M. (eds.) (2009). Minería y conflicto social. Lima: IEP, CIPCA, CBC, CIES.

De la Puente, L. (2015). Un avance transformador: la ampliación del aeropuerto Internacional Jorge Chávez y el reasentamiento del asentamiento humano «El Ayllu», Callao. Debates en Sociología, 41, 25-52.

Durand, A. (2010). De mineros a indígenas. Cambios en la organización social y la identidad de los trabajadores mineros de la Sierra Central. En A. Flores Galindo, D. Sulmont y N. Manrique, Jorge del Prado y los mineros de la Sierra Central. Testimonio sobre la masacre de Malpaso. Lima: Fondo Editorial del Congreso del Perú.

Ferguson, J. y Gupta, A. (2002). Spatializing States: Toward an Ethnography of Neoliberal Governmentality. American Ethnologist, 29(4), 981-1002. https://doi.org/10.1525/ ae.2002.29.4.981

Ferguson, J. (1994). The anti-politics machine: development, depoliticization, and bureaucratic power in Lesotho. Minnesota: University of Minnesota Press.

Foucault, M. (1979). On governmentality. Ideology and Consciousness, 6, 5-21.

Foucault, M. (2000). Defender a la sociedad. Curso en el Collège de France (1975-1976). Buenos Aires: Fondo de Cultura Económica. 
Garner, J. (ed.) (1992). The Company Town. Architecture and Society in the Early Industrial Age. Oxford University Press.

Geschiere, P. (2012). Política de la pertenencia: brujería, autoctonía e intimidad. México D.F.: Fondo de Cultura Económica.

Goffman, E. (1970). Internados. Ensayos sobre la situación social de los enfermos mentales. Buenos Aires: Amorrortu.

Helfgott, F. (2013). Transformations in labor, land and community: mining and society in Pasco, Peru, 20th century to the present. Tesis para obtener el grado de PhD en Antropología e Historia. University of Michigan.

Helfgott, F. (2017). La persistencia de lo social: los convenios laborales y los convenios comunidad-empresa en las zonas mineras de la Sierra Central. En O. Manky (ed.), Trabajo y sociedad. Estudios sobre el mundo del trabajo en el Perú. Lima: CISEPA-PUCP.

Herrera, C. (1986). Plan integral de vivienda para los asentamientos humanos mineros del centro del Perú ubicados en el eje La Oroya-Morococha. Lima: s.n.

Himley, M. (2012). Regularizing Extraction in Andean Peru: Mining and Social Mobilization in an Age of Corporate Social Responsibility. Antipode, 45(2), 394-416. https:// doi.org/10.1111/j.1467-8330.2012.01001.x

Sociedad Nacional de Minería Petróleo y Energía (2003). Privatizan Toromocho y Morococha. Informativo Mineroenergético, 12(3): 22 http://sisbib.unmsm.edu.pe/ bibvirtual/publicaciones/mineroener/v12_n3/priva_toro.htm

Huxley, M. (2008). Space and Government: Governmentality and Geography. Geography Compass, 2(5), 1635-1658. https://doi.org/10.1111/j.1749-8198.2008.00133.x

Instituto Nacional de Defensa Civil (2014). Reporte de peligro No 202-27/02/2014/COENINDECI. Peligro de movimiento en masa en el distrito de Morococha - Junín. Lima: INDECI.

Knight Piésold Consulting (2009). Minera Chinalco Perú S.A. Proyecto Toromocho. Estudio de Impacto Ambiental. Lima.

Kruijt, D. y Vellinga, M. (1988). La Cerro y el Proletariado Minero Metalúrgico. Lima: Comunidad Minera Centromín.

Lefebvre, H. (1991). The Production of Space. Oxford: Blackwell Publishing.

Mallon, F. (1983). The Defense of Community in Peru's Central Highlands: Peasant Struggle and Capitalist Transition, 1860-1940. Princeton University Press. https://doi. org/10.1515/9781400856046

Manky, O. (2017). El lugar importa: efectos de la movilidad en las estrategias sindicales. Revista Mexicana de Sociología, 79(1), 35-63.

Murray Li, T. (2007). The Will to Improve: Governmentality, Development, and the Practice of Politics. Durham \& Londres: Duke University Press.

Murray Li, T. (2017). After Development: Surplus Population and the Politics of Entitlement. Development and Change, 48(6), 1247-1261. https://doi.org/10.1111/ dech. 12344 
Ruiz, A. (2002). El proceso de privatizaciones en el Perú durante el periodo 1991-2002. Santiago de Chile: Instituto Latinoamericano y del Caribe de Planificación Económica y Social - ILPES.

Salas, G. (2008). Dinámica social y mineria: familias pastoras de puna y la presencia del proyecto Antamina (1998-2002). Lima: IEP.

Sanborn, C. y J. Dammert (2013). Extracción de recursos naturales, desarrollo económico e inclusión social: Perú. Lima: Centro de Investigación de la Universidad del Pacífico.

Scott, J. (1977). The Moral Economy of the Peasant: Rebellion and Subsistence in Southeast Asia. New Haven: Yale University Press.

Smith, J. y Helfgott, F. (2010). Flexibility or exploitation? Corporate social responsibility and the perils of universalization. Anthropology Today, 26(3), 20-23. https://doi. org/10.1111/j.1467-8322.2010.00737.x

Sociedad Nacional de Minería Petróleo y Energía (2003). Privatizan Morococha y Toromocho. Informativo Mineroenergético, 12(3), 22.

Sulmont, D. (1975). El movimiento obrero en el Perú / 1900-1956. Lima: Fondo Editorial PUCP.

Van Teijlingen, K. (2016). The "will to improve» at the mining frontier: Neo-extractivism, development and governmentality in the Ecuadorian Amazon. The Extractive Industries and Society, 3(4), 902-911. https://doi.org/10.1016/j.exis.2016.10.009

Zawada, A. (2010). Neoliberal Governmentality, Corporate Responsibility, and the Governing of Citizens in Nigeria: The case of ExxonMobil, Shell, and Chevron. Tesis de Maestría en Sociología. Universidad de Windsor, Ontario.

Zeiderman, A. (2012). On shaky ground: the making of risk in Bogotá. Environment and Planning A, 44, 1570-1588. https://doi.org/10.1068/a44283 